\title{
Chinese documentary as public culture
}

\author{
Luke Robinson
}

Received: 17 October 2014/Revised: 23 October 2014/ Accepted: 23 October 2014/

Published online: 28 November 2014

(C) Academy for International Communication of Chinese Culture 2014

\begin{abstract}
This article addresses the question of publicness in independent Chinese documentary, using examples from the lesbian and gay community as illustrations. It argues that changes in both form and subject matter in contemporary lesbian and gay independent documentary reflect the emergence of a socially engaged form that seeks to raise awareness through increased visibility. This can be understood in relation to Ching Kwan Lee and You-tien Hsing's concepts of "recognition" and "representation". Both of these concepts, however, are connected to ideas of the public and publicness. While there is a tradition of associating documentary with the public sphere understood in Habermasian terms, in China the public sphere as an institutional space has a problematic history. Instead, I suggest that other ways of understanding publicness are demonstrated by these documentaries: publicness as representational visibility, as performance in material space, and as an affective invocation of a shared viewing experience. This allows us some perspective not simply on the role of independent documentary in China, but the social significance of documentary more broadly conceptualized.
\end{abstract}

Keywords Documentary $\cdot$ China $\cdot$ Public space $\cdot$ Public sphere $\cdot$ Queer cinema

\section{Introduction: An emerging genre}

My point of departure for this article is the documentary short New Beijing, New Marriage (Xin Qianmen Dajie 2009) by Fan Popo and David Cheng. This film chronicles the performance of a gay wedding at Beijing's Qianmen Street on

L. Robinson $(\bowtie)$

Department of Media and Film, University of Sussex, Silverstone Building, Arts Road, Falmer,

East Sussex BN1 9RG, UK

e-mail: luke.robinson@sussex.ac.uk 
Valentine's Day 2009. It starts with the subjects-one male couple and one female couple-preparing for the event in a hotel room or flat somewhere in the city. It then tracks the couples to Qianmen, where they have wedding photos taken. Then, both the couples and the film crew directly engage with those people who have gathered to watch the event, asking them whether they support gay marriage and how they feel about homosexuality. Finally, the film ends with a montage of gay wedding stills from around the world, and an appeal for the legal recognition of same sex partnerships in China.

Located against the broader backdrop of Chinese documentary practice there is little that seems unusual about this film. It largely cleaves to the practices of live, location shooting - or xianchang-even as this practice has itself evolved within China. ${ }^{1}$ Nevertheless, on first viewing it struck me both as different from some of the earliest documentaries I had watched on the Chinese gay community, and similar to other, more contemporary independent documentaries that addressed analogous subject matter. Chinese documentaries on gay subjects from the early to mid 2000s often focused on transsexuals or fanchuan, the latter being cross-dressed performers, or what in English would sometimes be termed drag queens. Many of these documentaries also took place in or around gay bars, where these fanchuan performed. ${ }^{2}$ In contrast, New Beijing, New Marriage seemed part of a trend to broaden the material documented. Newer works did not exclude performers and performance from their subject matter, but they also turned the camera on the everyday experience of lesbians and gay men in China, both contemporary and historical. $^{3}$

The second important point of difference manifested in a shift in documentary aesthetics. Early documentaries about the gay community were either largely observational in their approach to their subject matter or quite experimental. For example, films like Jiang Zhi's Xiang Pingli (Xiang Pingli 2005) or Cui Zi'en's Night Scene (Yejing 2004) deliberately blurred the line between fiction and nonfiction through the use of techniques like re-enactment, or by mingling documentary and fictional storylines. ${ }^{4}$ Newer documentaries were often more reflexive: as in New Beijing, New Marriage, the filmmakers registered their presence on screen. In some ways, though, they were also more traditional. For example, standard broadcasting techniques like the talking head, the presenter, and the formal interview were

\footnotetext{
${ }^{1}$ For more detailed discussion of xianchang as a practice and aesthetic, as well as its evolution over time, see Berry (2007), Robinson (2010, 2013) and Wang (2012).

2 Examples here would include Zhang Yuan's Miss Jin Xing (Jin Xing Xiaojie 2000), Michelle Chen's The Snake Boy (Shanghai Nanhai 2002), Zhang Hanzi’s Tangtang (Tangtang 2004), Han Tao's Baobao (Baobao 2004), Gao Tian's Meimei (Meimei 2005), and Du Haibin's Beautiful Men (Renmian Taohua 2005).

3 Examples here are now too numerous to note, but would include Cui Zi'en's Queer China Comrade China (Zhi Tongzhi 2008), Fan Popo's Chinese Closet (Guizu 2009) and Mama Rainbow (Caihong Ban Wo Xin, 2012), the webcast Queer Comrades (Tongzhi Yi Fanren) (2007-), and the work produced under the auspices of the Queer University (Ku'er Daxue) media training programme.

${ }^{4}$ See the discussions of these techniques in Chao (2010) and Wang (2013), both of which focus specifically on queer documentary in China.
} 
deployed-techniques which were not part of the aesthetic repertoire of the early documentaries. 5

\section{Mainstreaming, social movement filmmaking, and the problem of publicness}

One response to these developments could be to position them as an attempt at "mainstreaming". Adopting a more conservative aesthetic might make the documentary form more palatable to a general audience. So too might shifting the focus from the more exotic elements of the gay community onto the everyday lives of gay men and women. These films could thus be said to resemble those Anglo-American documentary film and television programmes that, from the 1970s onwards, made gay men "visible" by emphasizing their similarity to mainstream society, rather than their problematic difference (Pullen 2007: 5-7). Certainly, many of the director of these films actually self-identify as gay, and are closely involved in community organizing with the Chinese gay community. ${ }^{6}$ But if we look more closely at these documentaries, it is harder to make such a hypothesis stick. New Beijing, New Marriage can hardly be considered a mainstream production in the commercial sense of the term: shot on a shoestring budget by non-professionals, it was not made for broadcast or theatrical release, and has thus only circulated informally, via homemade DVDs and independent film festivals. It is manifestly an independent work, produced and distributed outside official media structures, with no expectation of being presented to the media regulator for formal broadcast or exhibition. Similarly, while gay marriage may be part of the political mainstream in Western Europe and North America, this is not the case in China (or, indeed, much of the world). While such documentaries clearly function to make gay Chinese visible in new and distinct ways, mainstreaming as an explanatory framework cannot adequately capture the complexity of their internal dynamics. Instead, in many ways these films are closer to the social movement media that emerged in North America in the 1970s, in which gay filmmakers sought to document the emergence of a self-conscious gay culture for the first time (Waugh 1997).

Approaching these films as a form of social movement filmmaking allows us to frame them in relation to a set of slightly different questions. Given the limited space afforded to activism in the contemporary PRC, Ching Kwan Lee and You-tien Hsing (2010: 4) argue that social movements in China are driven by a desire to achieve "recognition" and "representation". Recognition involves the articulation, and formal acknowledgment of, the identities and needs of a particular social group. Representation involves a form of symbolic contestation: using written and audiovisual media to engage with mainstream discourses about this group. At times these two processes may be connected, particularly where the mainstream refuses to

\footnotetext{
5 See for example the use of the talking head in Queer China, Comrade China, or, to slightly different effect, in Zhou Ming's All About Gay Sex (Gay Na Huar 2010).

6 Fan Popo explicitly identifies as a gay man, and has been closely involved in gay rights activism in China.
} 
acknowledge the existence of certain communities, or frames their needs in specific ways. But central to both of these dynamics is the question of the public. "Recognition" in Lee and Hsing's sense requires a private identity to be made public: in other words, for this identity to be performed, articulated or displayed "in public". Here, public is clearly a location, a physical space outside the home where people can gather. In that sense, it is not dissimilar to the coffee houses where the emergent European bourgeoisie met to debate politics in Jurgen Habermas' (1989) classic formulation of the public sphere. Yet at the same time, this public is discursive. This assumption is explicit in the concept of representation, which suggests there is an intimate relationship between visibility and publicity. But it is also implicit in the idea that these films solicit recognition from a public that they address. Here, I am using public not in a Habermasian sense, but in that proposed by Michael Warner (2002): a social formation that is hailed into being through particular textual strategies on the part of a film, strategies which may include both argument and "structures of feeling" (Williams 1977). These are strategies that aim to activate a common social experience-the "general social horizon" (Negt and Kluge 1993: 2)—however temporarily or partially.

What I am suggesting is that publicness is a useful framework for analyzing the goals of documentaries like New Beijing, New Marriage. Indeed, thinking through publicness may help explain the particularities of documentary form and content identified at the beginning of this paper. What I therefore wish to do now is trace how publicness manifests in these films, and connect these manifestations to precisely such particularities. First, I want to consider issues of representation. How might this shift away from experimental formats be related to the question of publicness as visibility? Second, I want to consider space. While public space is usually understood in relation to film exhibition, it could equally apply to film production. A film shot on location, for example, might well be shot in public space. Thus, I want to address how these films might exploit space as a public infrastructure during filmmaking. Finally, I want to ask how these films might be a performative intervention into public culture. Do they hail a particular public into being? What strategies do they use to do so? While the examples considered here will focus exclusively on documentaries produced by and about the Chinese gay community, the issues explored are relevant to independent documentary in China more generally, and are not limited to this particular subgenre.

\section{Publicness: visibility, space, performance, affect}

First, I want to address the question of the emergence of a less experimental aesthetic. Arguably, this can in part be traced back to the background of these directors, and their lack of professional training. While many of the earliest directors of documentaries about the gay community trained at film school or in television, many younger filmmakers did not, and are often self-trained. ${ }^{7}$ But this

\footnotetext{
7 For example, though Fan Popo went the Beijing Film Academy he did not actually start practical filmmaking till after he had graduated, when he bought himself a video camera.
} 
aesthetic transition also relates to the issue of publicness as visibility. Cui Zi'en, for example, has been quite clear that his deliberate movement between fiction and nonfiction in a film like Night Scene was partly to prevent the real-life sex workers who appeared in the film from being identified off-screen (Voci 2010: 208 f.n. 28). These kinds of experimental practices made the identities of his subjects ambiguous. In contrast, the more realist style adopted by a documentary like New Beijing, New Marriage serves to clarify rather than confuse: there is little ambiguity here as to who the central subjects of this documentary are or what they are doing. The same is true of the use of techniques like the talking head. As Sarkar and Walker (2010: 5) have noted, talking heads are not naturalized, but are in their own way a type of performance. However, when used as a source of individual testimony, as Cui Zi'en does in his documentary Queer China, Comrade China, they make the narrative of gay history in China both audible and clearly "visible", rooting this story in a physical body that manifests unambiguously on the screen. In this sense, talking heads can be understood as kind of public poetics: a mode of documenting a particular form of social experience in a manner that is both sensible and present.

What is being made public is also significant, though. In many of the early films about fanchuan or transsexuals, there was a tendency towards voyeurism and spectacle. Sequences in which the camera inspected the bodies of the documentary's subjects-during surgery or performance-were not uncommon. Both Miss Jin Xing and Xiang Pingli contain scenes of gender reassignment surgery, for example, while in Du Haibin's Beautiful Men the director lingers somewhat uncomfortably backstage, watching his fanchuan subjects undress before and after performances. Nor were these scenes obscured by an experimental aesthetic: Du Haibin's film is shot almost entirely observationally, though his subjects do demonstrate a clear awareness of the camera. I think the refusal of such images in certain newer documentaries can be understood as an attempt to counter this discourse, replacing it with one in which potential objectification is less of a concern. This is underlined by moments when mainstream media discourse on homosexuality is addressed directly. In Queer China, Comrade China, for example, Cui Zi'en remediates highly critical comments about homosexuality made on television by the actor Sun Haiying. Cui edits these comments with footage of his own subjects disputing Sun's perspective. Montage thus becomes a way in which the film allows a counterdiscourse on homosexuality to emerge in dialogue, both visual and aural, with certain mainstream media representations. ${ }^{8}$

The second question is that of space and location. Digital media formatsparticularly the DVD and the electronic file-have been credited with enabling the movement of Chinese cinema across and between private and public space, through reduplication and circulation (Voci 2010: 15). Here, however, we can see how lightweight digital cameras facilitate this movement during the production process. As I noted earlier, New Beijing, New Marriage is characterized by a movement outwards, from interior to exterior space, across the course of the documentary. It starts in private space, moving through the semi-public space of a taxi, finally

\footnotetext{
${ }^{8}$ For further discussion of the use of montage by Chinese activist filmmakers as political technique see Qian (2014).
} 
concluding on Qianmen. This necessarily reflects the dynamic of the wedding event itself, which the directors are documenting. However, Cheng and Fan exploit this dynamic - and the mobility of the camera - to fashion their own identities in public as gay subjects. While the couples are being photographed, the filmmakers turn their camera on those watching, asking these onlookers questions about their attitude to the wedding, and towards homosexuality more generally. Posing such questions from behind the camera obviously marks the filmmakers as present on the site of filming. But it also aligns their subjectivity with that of the couples they are documenting. In effect, they are publicly calling attention to their own sexuality. Here, the mobility of the digital camera is used to support both a movement out into public space, and the public performance of identity within that space-a slippage between the public as institutional or material and the public as performative.

Finally, I would like to address the question of spectatorship. On location, both the couples' performance of wedding rituals, and the filmmakers' performance of filmmaking, directly hail a particular kind of viewing public into being. It is a sympathetic public, one that is asked to identify with the couples being filmedeven if in practice those hailed do not always respond this way, since the answers to the questions they are asked are varied, and not always positive. I would argue that the documentary itself does something similar. By concluding with a montage of gay wedding images from a number of different countries, New Beijing, New Marriage implicitly positions its viewing public as global and cosmopolitan, and as capable of understanding the importance of "connecting with the world" (jie gui). But it also makes an appeal based on common emotional experience. Love, the filmmakers suggest, is an affective state shared by everyone, regardless of sexual orientation; it is a point of connection that can be understood and appreciated by all. I would see this less as a conservative gesture, and more a move to depathologize such emotions in a context where they have been labelled as symptoms of mental illness. ${ }^{9}$ Either way, this is a move that clearly evokes particular affective experiences as part of the common social horizon. In the process, it positions traditionally marginalized social experience as one that is publicly shared.

\section{Conclusion}

In addressing the question of the publicness of certain Chinese documentary forms I have been working with a very specific subset of independent documentary-itself only one facet of Chinese non-fiction screen production. Even within this particular field, I have hardly provided a comprehensive overview. Nonetheless, I hope I have conveyed how one particular type of socially engaged filmmaking can make a selfconscious intervention into public culture. Documentary has historically been associated with publicness in the rather literal sense of the public sphere, a concept that focuses primarily on questions of reception at the expense of poetics and production. But, as a film like New Beijing, New Marriage demonstrates, there are

\footnotetext{
9 It was not until 2001, for example, that the Chinese Psychiatric Association agreed to strike homosexuality off its official list of psychiatric disorders.
} 
other ways - discursive, performative, spatial - in which non-fiction film can make an intervention of this nature. Tracing the forms and practices of socially committed documentary in China can thus provide us with a more complete picture of what such a contribution could be, and how it can be achieved.

\section{References}

Berry, C. (2007). Getting real: Chinese documentary, Chinese post-socialism. In Z. Zhang (Ed.), The urban generation: Chinese cinema and society at the turn of the twenty-first century (pp. 115-134). Durham: Duke University Press.

Chao, S.-Y. (2010). Performing gender, performing documentary in post-socialist China. In C. Yau (Ed.), Negotiating sexuality and gender in Mainland China and Hong Kong (pp. 151-175). Hong Kong: Hong Kong University Press.

Habermas, J. (1989). The structural transformation of the public sphere: An enquiry into a category of bourgeois society. Cambridge: Polity Press.

Lee, C. K., \& Hsing, Y.-T. (2010). Social activism in China: agency and possibility. In C. K. Lee \& Y.-T. Hsing (Eds.), Reclaiming chinese society: The new social activism (pp. 1-14). Abingdon: Routledge.

Negt, A., \& Kluge, O. (1993). Public sphere and experience (trans. Labanyi, P., Daniel, J. O. and Oksiloff, A.). Minneapolis: University of Minnesota Press.

Pullen, C. (2007). Documenting gay men: Identity and performance in reality television and documentary film. Jefferson and London: McFarlane and Company.

Qian, Y. (2014). Working with rubble: Montage, tweets and the reconstruction of an activist documentary. In M. Johnson, K. Wagner, T. Yu, \& L. Vulpiani (Eds.), China's i-generation: Cinema and moving image culture for the twenty-first century (pp. 181-196). London: Bloomsbury Academic.

Robinson, L. (2010). From 'public' to 'private': Chinese documentary and the logic of xianchang. In C. Berry, X. Lü, \& L. Rofel (Eds.), The new Chinese documentary film movement: For the public record (pp. 177-194). Hong Kong: Hong Kong University Press.

Robinson, L. (2013). Independent Chinese documentary: From the studio to the street. London and Basingstoke: Palgrave Macmillan.

Sarkar, B., \& Walker, J. (2010). Introduction: Moving testimonies. In B. Sarkar \& J. Walker (Eds.), Documentary testimonies: Global archives of suffering (pp. 1-34). London and New York: Routledge.

Voci, P. (2010). China on video: Smaller-screen realities. Abingdon and New York: Routledge.

Wang, Q. (2012). Performing documentation: Wu Wenguang and the performative turn of New Chinese Documentary. In Y. Zhang (Ed.), A companion to Chinese cinema (pp. 299-317). Malden: Blackwell Publishing.

Wang, Q. (2013). Embodied visions: Chinese queer experimental documentaries by Cui Zi'en and Shi Tou. Positions, 21(3), 659-681.

Warner, M. (2002). Publics and counterpublics. Cambridge: The MIT Press.

Waugh, T. (1997). Walking on tippy toes: Lesbian and gay liberation documentary of the post Stonewall period 1969-84. In C. Holmlund \& C. Fuchs (Eds.), Between the sheets, in the streets: Queer, lesbian, gay documentary (pp. 107-124). Minneapolis: University of Minnesota Press.

Williams, R. (1977). Marxism and literature. Oxford: Oxford University Press. 